\title{
Mattoso Câmara Jr. e a Palavra Prosódica*
}

\author{
(Mattoso Câmara Jr. and the Prosodic Word)
}

Leda BISOL

$(P U C-R S)$

\begin{abstract}
The subject of this paper is the phonological word and its interaction with the morphological word. The dimension, the domain and the functions of the phonological word are discussed following the principles of Prosodic Theory (Booij 1983), (Nespor E Vogel 1986). Câmara Jr's statements regarding Brazilian Portuguese are the basis of the considerations.
\end{abstract}

KEY-WORDS: Prosodic constituent; Phonological word; Morphological word.

RESUMO: Este artigo que se detém no conceito de palavra fonológica, fundamentandose na Teoria Prosódica (Booij 1983), (Nespor E Vogel 1986), relembra Mattoso Câmara Jr., o primeiro entre nós a fazer específica diferença entre dois tipos de palavra, a que diz respeito aos morfemas, a que diz respeito à presença de um acento. Discutemse a interação entre as duas unidades, a dimensão e as funções da palavra fonológica. Nestas simples linhas, nossa homenagem ao grande mestre de quem tivemos a felicidade de ser aluna.

Palavras-Chave: Constituinte prosódico; Palavra fonológica; Palavra morfológica.

\section{Introdução}

Diz Mattoso Câmara, em sua descrição do sistema fonológico do português do Brasil, que necessário se faz distinguir a palavra morfológica da palavra fonológica. A primeira compreende palavras lexicais, como nome, adjetivo e verbo, classes abertas, e palavras funcionais como preposição, conjunção e determinativos, classes fechadas. A segunda distingue palavras com acento e sem acento, respectivamente palavras fonológicas e clíticos.

* Este estudo faz parte de uma pesquisa que vem sendo realizada sob os auspícios do CNPq. 
Este estudo firma-se nessa distinção e discute a interação entre palavra morfológica e palavra fonológica, cujos limites nem sempre são coincidentes, o que motiva as seguintes perguntas:

Quais os elementos básicos da palavra fonológica?

Qual o tamanho possível de uma palavra fonológica?

Qual o seu domínio de regras?

Com a atenção voltada para essas questões, o artigo desenrola-se em três partes, a primeira trata dos elementos constitutivos da palavra fonológica; a segunda, de suas possibilidades de tamanho e a terceira de seu domínio de regras.

\section{Dos elementos básicos da palavra prosódica}

Segundo Nespor and Vogel (1986:108), a palavra fonológica é o constituinte mais baixo da escala prosódica que representa a interação entre morfologia e fonologia. De acordo com Strict Layer Hypothesis ${ }^{1}$ em que se fundamenta essa escala, cada constituinte prosódico é a unidade composta de uma ou mais unidades da categoria imediatamente inferior. Por conseguinte, o pé ou os pés devem estar exaustivamente contidos na palavra que os domina.

(1) Escala prosódica

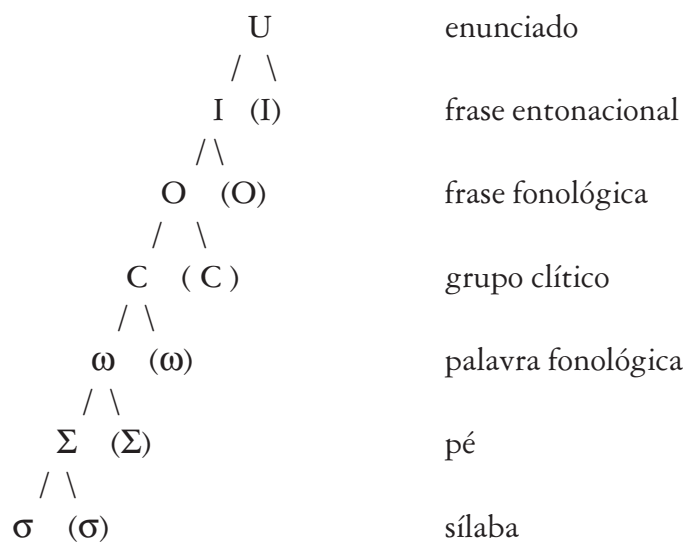

Strict Layer é o princípio que exige que uma unidade de um dado nível da escala prosódica esteja exaustivamente contida no nível superordenado do qual ela faz parte. 
Nessa perspectiva, a menor unidade é a sílaba, a qual combina dois ou mais segmentos em torno de um pico de sonoridade; sílabas agrupam-se para formar pés; o pé ou os pés métricos vão constituir a palavra fonológica que se combina com um clítico para formar o grupo clítico e assim sucessivamente até chegar à unidade máxima, o enunciado. Cada unidade prosódica, por sua vez, é um constituinte imediato que, por definição, expressa uma relação de dominância em termos de forte/fraco. Na sílaba, o forte é o membro de maior sonoridade, a rima, e o fraco é o ataque; no pé, apenas uma sílaba é forte; na palavra, o forte é a sílaba com acento projetado pelo pé métrico e o fraco são as sílabas não acentuadas.

Em (2) analisam-se os elementos que entram na constituição da palavra fonológica. Na primeira linha, dispõem-se as sílabas; na segunda, os pés métricos e na terceira, o acento. A sílaba agrupa os sons em material lingüístico; o pé métrico agrupa as sílabas ritmicamente e projeta o acento da palavra.

(2) Elementos constitutivos da palavra fonológica

\begin{tabular}{|c|c|c|c|c|c|c|}
\hline \multicolumn{3}{|c|}{ a. bor. bo. le. ta } & b. pa. re.de & c. co. ro. nel & d. lam. pa. $<$ da $>$ & sílaba \\
\hline$(*$ & .) $(*$ & .) & $\left(\begin{array}{ll}* & .\end{array}\right)$ & $(* \quad).(*)$ & $(*$ & pé \\
\hline( & $*$ & ) & * ) & $*)$ & $(*$ & acento \\
\hline
\end{tabular}

Admitindo-se a sensibilidade ao peso da sílaba final, essa atrai o acento em palavras acabadas em sílaba ramificada (2d). Em palavras terminadas em sílaba leve, forma-se um pé binário de cabeça à esquerda. É o que lemos acima: a primeira linha mostra, através de pontos, as sílabas segmentadas; a segunda indica com asterisco o elemento forte e a terceira, o acento da palavra. Sílabas com colchetes angulados, ditas extramétricas, são ignoradas pelas regras de acento. Da direita para a esquerda, as palavras são analisadas em pés binários de cabeça à esquerda, atribuído primeiramente um asterisco à sílaba ramificada final (2d). Como vemos, o elemento fundamental da palavra fonológica é o pé métrico que determina o acento, o seu identificador. Mas como pé métrico se define pelo nível imediatamente inferior, que é a sílaba, ambos, sílaba e pé métrico, são os elementos constitutivos da palavra fonológica. Todavia vale observar que, embora se pressuponha interação entre palavra morfológica e palavra fonológica, há uma diferença fundamental, a primeira está relacionada ao significado; a segunda, ao ritmo. 
O grande problema, no âmbito da língua oral, é que por vocábulo se entendem duas entidades diferentes. De um lado, há o vocábulo fonológico, que corresponde a uma divisão espontânea na cadeia da emissão vocal. De outro lado, há o vocábulo formal ou mórfico, quando um segmento fônico se individualiza em função de um significado específico que lhe é atribuído na língua. Há certa correspondência entre as duas entidades, mas elas não coincidem sempre e rigorosamente (Mattoso Câmara 1969:34).

Para identificar a palavra fonológica, Mattoso Câmara (1969: 35) propõe uma pauta prosódica delineada em termos de algarismos. Designa 3 e 2 para acentos fortes, 1 para a pretônica e 0 para átonas após o acento, salientado que "Em português, o vocábulo fonológico depende da força de emissão das suas sílabas. Essa força é que se chama acento."

Em uma seqüência de segmentos ininterruptos, essa pauta permite identificar palavras fonológicas:

(3)

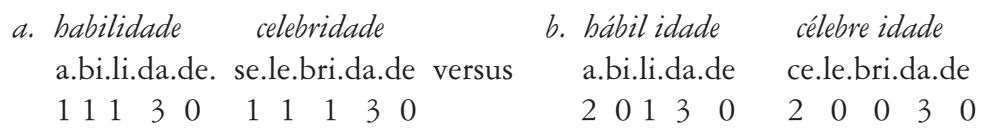

Como vemos, a isomorfia entre palavra fonológica e palavra prosódica existe em (3a) mas não existe em (3b). Mais adiante (1969:36), com respeito aos clíticos, afirma: "as pessoas mal alfabetizadas de hoje e os copistas medievais, escrevendo olivro, sefala, falasse, sem espaço em branco, estão adotando um critério fonológico."

O clítico não é uma forma livre porque não pode funcionar isoladamente como comunicação suficiente, mas também não é uma forma presa, pois entre ele e a palavra em que se apóia outras palavras podem intercalar-se. Classifica-o como forma dependente, analisando o grupo como palavra fonológica. Inversamente, as palavras compostas, guarda-chuva, por exemplo, são dois vocábulos fonológicos e um só vocábulo mórfico (Mattoso Câmara 1969:37).

Uma das questões mais discutidas na prosódia é o estatuto do grupo constituído de uma palavra com acento e outra ou outras sem acento que estão prosodicamente relacionadas. Para Nespor and Vogel (1986), o grupo clítico, assim o chamam, é o domínio prosódico subseqüente à palavra fonológica. Para outros fonólogos, entre os quais Selkirk (1984), Peperkamp 
(1997) e Vigário (2001), esse domínio não se sustenta. A prosodização do clítico no nível da palavra, o que corresponderia à visão de Mattoso, ou no nível subseqüente da escala prosódica, proposta de Nespor and Vogel, ou ainda no nível da frase, vem produzindo interessantes artigos, mostrando que, quanto aos clíticos, da mesma forma que quanto aos compostos, as línguas particulares têm de ser ouvidas, pois há comportamentos diversificados. Não entraremos nestas duas questões que demandam tempo e espaço, e vão além dos objetivos deste breve artigo que se limita às noções básicas de palavra fonológica, em sua forma mais simples.

Apontados os elementos constitutivos da unidade em questão, terminemos esta seção com duas definições de palavra fonológica, uma em termos de língua particular e outra em termos de língua em geral.

O vocábulo fonológico é uma entidade prosódica, caracterizada por um acento e dois graus de tonicidade possíveis, antes e depois do acento. Corresponde no plano mórfico à forma livre de Bloomfield. (Mattoso Câmara 1975: 38).

A palavra fonológica é o nível da hierarquia prosódica que representa o mapeamento entre os componentes morfológicos e fonológicos de uma gramática. (Nespor and Vogel 1986: 141).

\section{O tamanho de uma palavra fonológica}

Não existe consenso quanto ao tamanho de uma palavra fonológica. Para Booij (1983), há três possibilidades: igual ao elemento terminal de uma árvore sintática, maior ou menor do que ele. Para Nespor \& Vogel (1986: 110) só existem duas dimensões: igual ou menor.

O grego e o latim, afirmam Nespor and Vogel, são línguas que mantêm a isomorfia referida. $\mathrm{O}$ acento principal aplica-se da mesma forma em palavra simples, derivada e composta e os dois membros de um composto pertencem ao mesmo domínio prosódico, isto é, formam uma só palavra fonológica.

Palavras fonológicas menores do que o elemento terminal de uma árvore sintática são encontradas em várias línguas, entre as quais, segundo as referidas autoras, sânscrito, turco e italiano. Nas duas primeiras, cada raiz de um composto forma palavra fonológica independente, juntando-se os afixos à última raiz. No italiano, prefixos acabados em vogais constitu- 
em por si sós palavras fonológicas, enquanto prefixos acabados em consoantes se anexam a uma raiz para constituir com ela uma só unidade prosódica.

No português, como as línguas do segundo grupo, a isomorfia nem sempre se mantém. Diferentemente do italiano, que distingue prefixos acabados em consoante de prefixos acabados em vogal, os dados do português mostram que o mesmo prefixo se comporta ora como palavra independente ora não, dependendo do grau de coerência. Observemo-los em (4), levando em conta as variedades do português brasileiro que, em posição pretônica, não possui vogais médias baixas, porque são neutralizadas em favor da média alta, como ocorre no dialeto carioca e nos falares de estados circunvizinhos até o extremo sul.

(4) a. Forma presa

$$
\begin{aligned}
& \text { i) } \operatorname{pr\varepsilon }+\text { fixo }>\text { prefixo } \\
& \text { pre }+ \text { fixo }>\text { pretônica } \\
& \text { pre }+ \text { sentir }>\text { pressentir } \\
& \text { pre }+ \text { dispor }>\text { predispor } \\
& \text { pre }+ \text { onceito }>\text { preconceito } \\
& \text { ii) pos }+ \text { fácio }>\text { posfácio } \\
& \text { pos }+ \text { por }>\text { pospor } \\
& \text { pos }+ \text { ponto }>\text { posponto } \\
& \text { pos }+ \text { posição }>\text { posposição } \\
& \text { pos }+ \text { céfalo }>\text { poscéfalo } \\
& \text { pre }+ \text { estréia }>\text { pre - estréia } \\
& \text { pre }+ \text { vestibular }>\text { pr } \varepsilon \text { - vestibular } \\
& \text { pre }+ \text { escola }>\text { pre - escola } \\
& \text { pre +diluviano }>\text { pre-diluviano } \\
& \operatorname{pr\varepsilon }+\text { coma }>\text { pre - coma } \\
& \text { pos }+ \text { lexical }>\text { pos - lexical } \\
& \text { pos }+ \text { doutorado }>\text { pos - doutorado } \\
& \text { pos }+ \text { guerra }>\text { pos-guerra } \\
& \text { pos }+ \text { textual }>\text { pos - textual } \\
& \text { pos }+ \text { operatório }>\text { pos - operatório }
\end{aligned}
$$

b. Forma livre

Em (4ai, ii), o prefixo pre e pos sofrem a neutralização, comportandose como sílaba pretônica da palavra; em outros termos, juntam-se à palavra seguinte, formando com ela uma só palavra fonológica. Em (4bi, ii), ao contrário, mostram- se autônomos. A vogal média baixa é mantida como se o prefixo fosse membro de um composto, pois prefixo e raiz com seu afixo formam palavras separadas.

Por conseguinte, a prefixação pode resultar num só vocábulo fonológico ou numa justaposição Nesse último caso, o prefixo é um vocábulo fonológico de per si, como diz Mattoso Câmara (1969:39). Eis aí um caso em que a palavra fonológica é menor do que o constituinte terminal de 
uma árvore sintática. Palavras fonológicas maiores do que a contraparte referida são encontradas no resultado da ressilabificação, como veremos mais adiante. Mas na acepção de Mattoso, um bom exemplo de uma palavra fonológica maior do que a morfológica está em grupos do tipo de seda ou fala-se, em que os dois morfos formam uma só palavra prosódica. Contrariamente, no composto, há um só vocábulo morfológico e dois fonológicos, fato já mencionado. Assim, diz Mattoso Câmara (1969:37), atribuindo a pauta (2030) a ambos os exemplos:

Por outro lado, no chamado composto por justaposição, temos a ocorrência oposta. Dois vocábulos fonológicos passam a constituir um só vocábulo formal. Assim, guarda-chuva tem a mesma pauta acentual que grande chuva.

Diferentemente do grego e do latim em que, segundo Nespor and Vogel, o composto tem a mesma extensão do elemento terminal de uma árvore sintática, mas da mesma forma que o sânscrito e o turco, no português falta correspondência de bordas entre as duas entidades em cotejo, pois cada membro de um composto formado por justaposição, esteja acompanhado de afixos ou não, é domínio do pé que projeta seu acento individual. Vemos, pois, que palavra fonológica e palavra morfológica nem sempre andam em perfeita simetria, embora essa seja a base daquela.

Passemos a considerar as funções da palavra fonológica. De acordo com Booij (1983: 270-271), a palavra fonológica tem três funções: Primeiro, é portadora de relações de proeminência como (5 ) exemplifica.

(5)

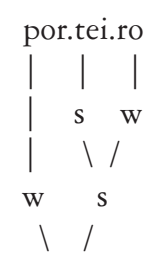

$\omega$

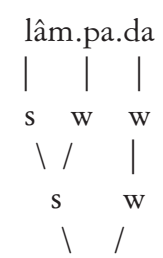

$\omega$

Segundo, é domínio de aplicação de regra fonológica. Em português, é o domínio das regras de neutralização, harmonia vocálica e abaixamento datílico, entre outras.

Terceiro, é o domínio de restrições fonotáticas: Há línguas que não aceitam monossílabos como palavra fonológica. Há outras que impõem um esqueleto rítmico. 
No português brasileiro, em palavras não monossilábicas, o esqueleto rítmico é o identificador da palavra prosódica. Em termos de Mattoso Câmara, expressa-se por (1 2/3 0), cujas bordas (1) e (0) indicam respectivamente início e fim de vocábulo e onde $(2,3)$ são destinados às sílabas relativamente mais fortes, portadoras de acento secundário (2) e acento primário (3), o único indispensável. Assim, em perigoso e relâmpago, as pautas (1130) e (1300), com (1) e (0) repetidos, o primeiro e o último são os indicadores de borda inicial e final respectivamente.

Portanto, a palavra fonológica, de acordo com suas características, pode ser vista como i) um expoente de proeminência relativa em virtude da relação sintagmática de seus membros; ii) uma entidade rítmica em virtude da organização métrica de suas sílabas e iii) um domínio de regras. Esse último foi discutido amplamente por Nespor and Vogel (1986).

Deixando-se o grupo clítico em um domínio específico, e olhando para a palavra fonológica como unidade do nível lexical, concorda-se com Nespor and Vogel: como domínio de regras só possui duas dimensões, igual a sua contraparte ou menor do que ela. Mas, se levarmos em conta as duas outras funções, seguindo Booij, então surge, no pós-lexico, a unidade maior. ${ }^{2}$

Consideremos a ressilabificação. Comum às línguas românicas, é o processo que acontece quando a segunda palavra começa por vogal, como (6) exemplifica.

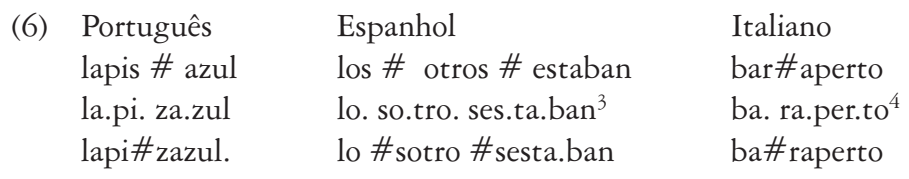

Nos três casos, uma palavra foi encurtada e outra aumentada, perdendo-se o alinhamento das bordas final e inicial da palavra fonológica e da

\footnotetext{
2 No pós-lexico, não se discute a isomorfia palavra morfológica / palavra fonológica, se formos fiéis aos cânones da Fonologia Lexical, uma vez que nesse nível todos os colchetes indicadores de limites morfológicos foram apagados no fim do léxico pela Convenção de Apagamento de Colchetes. $\mathrm{Na}$ Teoria da Otimidade, todavia, o alinhamento de colchetes entre os quais o da palavra lexical e da palavra prosódica é um recurso, sempre disponível, controlado por restrições.

Cf. Harris 1983

4 Cf. Peperkamp 1997
} 
palavra morfológica. Especificamente a correspondência de bordas préestabelecida na alínea i) é perdida na alínea ii) por ressilabificação, que consiste em tornar a silabificar segmentos previamente silabificados, resultando iii) quebra de limites. Se, como vimos, a palavra fonológica se define por sua constituição prosódica (sílaba, pé e apenas um acento primário), ignorando informação dos morfos, segue-se naturalmente que figuram como palavras fonológicas zazul, sestaban e raperto. ${ }^{5}$

Note-se que em português existe o contraste kazalkasa, karu>karru, e que na organização ou reorganização das sílabas, entre vogais operam as regras s $>$ z e r > rr, tanto na silabificação, quanto na ressilabificação. A diferença reside nos domínios e conseqüentes resultados. A primeira ocorre cedo no léxico, ou seja, no domínio da palavra fonológica, por acréscimo de afixos, mar > mares, formando um novo par, palavra morfológica e fonológica; a segunda, mais tarde, no pós-léxico, sem interação com a morfologia, ou seja, entre palavras fonológicas mar azul > marazul. Vale ainda lembrar uma diferença: enquanto na silabificação as vogais /? ,?/ são neutralizadas, na ressilabificação são preservadas: $s(0) l+$ aço $>$ solaço, mas s. (o). alto $>$ s. (o). lalto. ${ }^{6}$

Podemos, pois, dizer, admitindo a posição de Booij (1983) e de Peperkamp (1997: 30) que, assim como há palavras fonológicas menores do que as morfológicas correspondentes, também há maiores, pois no português, como no italiano e no espanhol, quando na ressilabificação ocorre o alongamento de uma palavra prosódica e a diminuição de outra, não respeitando Strict Layer, a consoante final não só se torna parte da sílaba inicial da palavra seguinte mas também da palavra prosódica a que esta sílaba pertence.

Observe-se que no processo de ressilabificação podem preservar-se todos os segmentos inalterados ou perder alguns.

\footnotetext{
5 Embora palavra fonológica e palavra prosódica venham sendo usadas como sinônimos, talvez neste caso o termo mais apropriado seja palavra prosódica.

6 A vocalização de lateral posvocálica tende a ser geral no português brasileiro, mas no sul do País a lateral velar ainda se mantém como regra variável.
} 


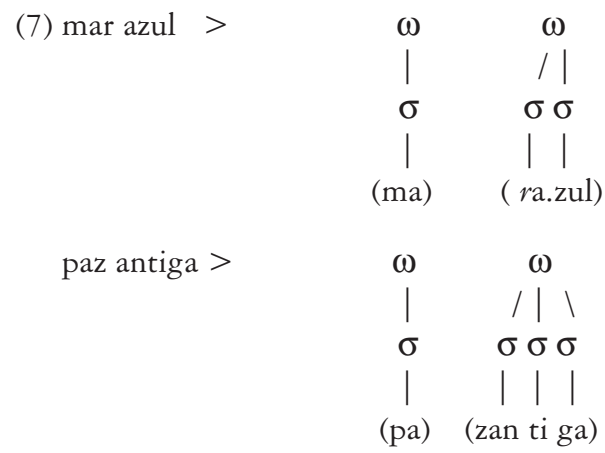

Em mar azul (ma.) $\omega($ ra.zul) $\omega$, assim como em bar aberto $>(b a.) \omega$ (ra.ber.to) $\omega$, e paz antiga (pa) $\omega$ (zantiga) $\omega$, perde-se o alinhamento dos limites entre as palavras cotejadas, sem perda de material fonético ou morfológico, o que garante a preservação de significado. Mas há casos de perda de material fonético sem prejuízo de significado, como se constata no sândi vocálico:

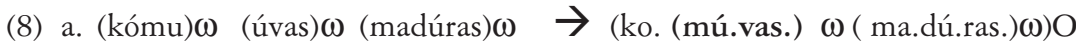
como uvas maduras

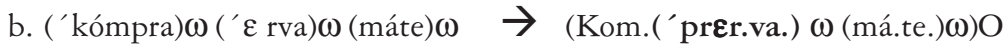
compra erva mate

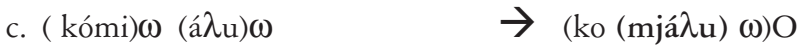
come alho

Em (8a), as vogais idênticas degeminam e a consoante flutuante torna-se o ataque da sílaba inicial da palavra seguinte, aumentando-a. Perdese uma sílaba e conseqüentemente material fonético, com o encurtamento da vogal, pois o português não possui vogais longas. Por elisão da vogal /a/, em (8b), da mesma forma, a coda da sílaba final de uma palavra passa a ser o ataque da sílaba inicial da palavra seguinte, aumentando o seu domínio. Novamente perde-se uma sílaba e material fonético, pois a vogal /a/ foi apagada. Diferentemente em (8c), para resolver o hiato, cria-se um ditongo, mas não se perde material, embora a cadeia passe a ter uma sílaba a menos.

Em nenhum dos casos houve perda de conteúdo semântico. Nos dois primeiros, o morfema modo-temporal apagado fica representado na vogal 
que persiste por identidade de traços; no segundo, o morfema não foi lesado como entidade portadora de significado porque apenas um de seus membros é apagado. Mas o importante a ser observado é que os valores de significado de um morfema ultrapassam fronteiras prosódicas.

Encontramos, pois, a palavra fonológica em três tamanhos: igual a sua contraparte, menor ou maior.

Finalizemos esse item com registros antigos que se devem a Souza da Silveira (1952):

( 9 ) “Desdo Trópico ardente ao Cinto frio" (Camões, Lus.129, 8)

“assi que dámbolos olhos Martin Alvitez cegou” (Afonso o Sábio. C S M, 60)

“ e dizem quisto é o que quis dizer Platão (Heitor Pinto, Im , tomo I, 462)

\section{A palavra fonológica como domínio de regras}

As regras mais citadas que têm por domínio a palavra fonológica são as neutralizações: a que converte o sistema de sete vogais em cinco, por perda de distinção entre as médias e é visível na pretônica, $b \varepsilon l o>b e l e z a$, sol $>$ solaso e a que anula de todo a vogal média, reduzindo a três vogais o sistema da átona final, verde $>$ verdi, bolu $>$ bolu. É no domínio da palavra fonológica que elas operam, pois uma e outra dependem do grau de atonicidade da sílaba.

A elevação da vogal pretônica por força da presença de uma vogal alta, uma regra de aplicação variável mas de uso geral em todos as variedades do português brasileiro, geralmente referida como harmonização vocálica, também tem por domínio a palavra fonológica, pois somente se aplica em sílabas átonas, sem atravessar fronteiras: pepino $>$ pipino, coruja $>$ curuja.

$\mathrm{O}$ abaixamento datílico, esqueleto $>$ esquet'les tico e o abaixamento espondeu, \{'dol\}cil > \{do\}cilidade, ret'portter $>$ re(por\}tagem também olham para a relação sílaba com acento e sílaba sem acento. O primeiro atua em proparoxítonas, o segundo, em paroxítonas acabadas em consoante, ambos pressupondo um condicionamento prosódico: a sílaba tônica.

A inserção de um glide para evitar o hiato área $>$ areia, passeo $>$ passeio, europea $>$ européia, que ocorre quando a primeira vogal é acentuada, tam- 
bém é uma regra do domínio da palavra, diferentemente da quebra de hiato por conversão de uma das vogais em glide, que tanto ocorre dentro da palavra, diabo $>$ djabo, teatro $>$ tjatro, quanto entre palavras, este arco $>$ estjarco, vende ameixas $>$ vendjameixas.

Citamos algumas regras atuantes no português brasileiro que têm condicionamento prosódico e que mostram a importância da palavra fonológica no sistema da língua, sem a pretensão de esgotar o assunto.

Em suma, a palavra fonológica distingue-se pelo contorno prosódico delineado a partir do acento primário de que é portadora e representa na hierarquia prosódica o primeiro nível em que morfologia e fonologia interagem. Embora a cadeia prosódica seja mapeada na cadeia morfológica, a assimetria entre uma e outra nem sempre se mantém seja como domínio de regras, seja como resultado de ressilabificação. A palavra fonológica tem, pois, dimensões que extrapolam os limites da palavra lexical, ou seja, da palavra morfológica.

E-mail: bisol@pucrs.br

\section{REFERÊNCIAS}

BooIJ, G. 1983. Principles and parameters in prosodic phonology. Linguistics, 21: 249-280.

Mattoso CÂmara Jr., Joaquim. 1969. Problemas de Lingüística Descritiva. Petrópolis: Vozes.

1975. História e Estrutura da Lingua Portuguesa. Rio de Janeiro: Padrão.

Nespor, M. and I. Vogel. 1986. Prosodic Phonology. Dordrecht: Foris.

Peperkamp, S. 1997. Prosodic Words. HIL Dissertation 34. The Hague: Holland Academic Graphics.

SelKIRK, E. 1984. Phonology and Syntax. The Relation between Sound and Structure. Cambridge, MA: MIT Press.

Silveira, Souza da. 1952. Fonética Sintática. Rio de Janeiro: Organização Simões.

Vigário, M. C. 2001. The prosodic Word in European Portuguese. Dissertação de Doutoramento. Faculdade de Letras, Lisboa. 